\title{
Article
}

\section{Fetal Cardiac Interventions-Are They Safe for the Mothers?}

\author{
Beata Rebizant ${ }^{1, *}\left(\mathbb{D}\right.$, Adam Koleśnik ${ }^{2,3,4}$, Agnieszka Grzyb ${ }^{2,5}$ [, Katarzyna Chaberek ${ }^{1}$, Agnieszka Sękowska ${ }^{1,6}$, \\ Jacek Witwicki ${ }^{7}$, Joanna Szymkiewicz-Dangel ${ }^{2}\left(\mathbb{D}\right.$ and Marzena Dębska ${ }^{1,8, *} \mathbb{1}$
}

1 2nd Department of Obstetrics and Gynecology, Centre of Postgraduate Medical Education, 01-809 Warsaw, Poland; chaberek.katarzyna@gmail.com (K.C.); drsekowska@gmail.com (A.S.)

2 Department of Perinatal Cardiology and Congenital Anomalies, Centre of Postgraduate Medical Education, US Clinic Agatowa, 03-680 Warsaw, Poland; akolesnik@cmkp.edu.pl (A.K.); agagrzyb@gmail.com (A.G.); jdangel@cmkp.edu.pl (J.S.-D.)

3 Cardiovascular Interventions Laboratory, The Children's Memorial Health Institute, 04-730 Warsaw, Poland

4 Department of Descriptive and Clinical Anatomy, Medical University of Warsaw, 02-004 Warsaw, Poland

5 Department of Cardiology, The Children's Memorial Health Institute, 04-730 Warsaw, Poland

6 Pain Clinic, Department of Anesthesiology and Intensive Care, Centre of Postgraduate Medical Education, 00-416 Warsaw, Poland

7 Department of Neonatology, Centre of Postgraduate Medical Education, 01-809 Warsaw, Poland; jacek.witwicki@bielanski.med.pl

8 Department of Gynecologic Oncology and Obstetrics, Centre of Postgraduate Medical Education, 00-416 Warsaw, Poland

* Correspondence: Correspondence: beata.rebizant@gmail.com (B.R.); marzena@debska.me (M.D.); Tel.: +48-508130737 (B.R.); +48-607449302 (M.D.)

check for updates

Citation: Rebizant, B.; Koleśnik, A.; Grzyb, A.; Chaberek, K.; Sękowska, A.; Witwicki, J.; Szymkiewicz-Dangel, J.; Dębska, M. Fetal Cardiac Interventions-Are They Safe for the Mothers? J. Clin. Med. 2021, 10, 851. https://doi.org/10.3390/jcm10040851

Academic Editor: Erich Cosmi

Received: 29 January 2021

Accepted: 15 February 2021

Published: 19 February 2021

Publisher's Note: MDPI stays neutral with regard to jurisdictional claims in published maps and institutional affiliations.

Copyright: (C) 2021 by the authors Licensee MDPI, Basel, Switzerland. This article is an open access article distributed under the terms and conditions of the Creative Commons Attribution (CC BY) license (https:// creativecommons.org/licenses/by/ $4.0 /)$.

\begin{abstract}
The aim of fetal cardiac interventions (FCI), as other prenatal therapeutic procedures, is to bring benefit to the fetus. However, the safety of the mother is of utmost importance. The objective of our study was to evaluate the impact of FCI on maternal condition, course of pregnancy, and delivery. 113 mothers underwent intrauterine treatment of their fetuses with critical heart defects. 128 percutaneous ultrasound-guided FCI were performed and analyzed. The patients were divided into four groups according to the type of FCI: balloon aortic valvuloplasty (fBAV), balloon pulmonary valvuloplasty (fBPV), interatrial stent placement (IAS), and balloon atrioseptoplasty (BAS). Various factors: maternal parameters, perioperative data, and pregnancy complications, were analyzed. There was only one major complication-procedure-related placental abruption (without need for blood products transfusion). There were no cases of: procedure-related preterm prelabor rupture of membranes (pPROM), chorioamnionitis, wound infection, and anesthesia associated complications. Tocolysis was only necessary only in two cases, and it was effective in both. None of the patients required intensive care unit admission. The procedure was effective in treating polyhydramnios associated with fetal heart failure in six out of nine cases. Deliveries occurred at term in $89 \%, 54 \%$ were vaginal. The results showed that FCI had a negligible impact on a further course of pregnancy and delivery.
\end{abstract}

Keywords: fetal cardiac interventions; fetal interventions; fetal therapy; maternal safety; fetal valvuloplasty; stent placement; congenital heart disease; critical aortic stenosis; hypoplastic left heart syndrome; pulmonary atresia and intact ventricular septum

\section{Introduction}

The majority of available data concerning fetal cardiac interventions (FCI) describe the effect of these procedures on the fetal outcome. Data concerning the influence of FCI on maternal condition are very limited.

The aim of fetal cardiac interventions is to change the natural course of some critical congenital heart defects (cCHD) [1-5] and, hence, to save fetal or neonatal life. Some CHD, if untreated prenatally, lead to irreversible changes in the anatomy and function of the cardiovascular system. In the case of severe aortic or pulmonary stenosis, the goal is to 
diminish the negative impact of pressure overload on the function and development of the left or right ventricle, respectively [3,6,7]. Opening the valve by ballooning unloads the ventricle and increases flow, allowing for better growth of the ventricle and vessels, according to the "no flow-no growth" theory [8]. In the cases of left heart disease with closed foramen ovale, the aim of the intervention is to prevent the damage of pulmonary vessels that would inevitably lead to life-threatening pulmonary hypertension and often irreversible anatomical changes in pulmonary circulation [5,9-12]. However, in such cases, FCI also aims to improve the maternal condition, as these defects commonly cause severe polyhydramnios, which may significantly affect maternal health and the course of pregnancy.

An increasing number of international data suggest that FCI enables the improvement of fetal condition $[13,14]$. This is a unique situation in which the fetus requires treatment, but the healthy mother is exposed to the risk of potential complications. Therefore, ensuring the woman's safety is very important. The aim of our study is to assess the impact of FCI on maternal condition, as well as the further course of pregnancy and delivery.

\section{Materials and Methods}

\subsection{General Study Design}

Between June 2011 and April 2020, our team performed 128 percutaneous ultrasoundguided fetal cardiac interventions on 113 fetuses [15]. This research included all of the patients undergoing FCI in the 2nd Department of Obstetrics and Gynecology of the Centre of Postgraduate Medical Education in Bielanski Hospital, Warsaw, Poland. Prospective and retrospective analyses of medical records and patients' charts were performed. The Ethical Committee of the Centre of Postgraduate Medical Education approved the study. The mothers signed an informed consent form and an agreement for the experimental therapy.

Prior to hospital admission, all of the FCI candidates had undergone fetal echocardiography at the Department of Perinatal Cardiology and Congenital Anomalies, Centre of Postgraduate Medical Education, US Clinic Agatowa, Warsaw, Poland.

\subsection{Patients/Study Population}

The patients were qualified for the intervention based on published inclusion criteria $[6,16-18]$ by experienced pediatric cardiology and maternal-fetal medicine specialists.

The maternal exclusion criteria were, as follows: any diseases that increment the maternal risk of either the procedure or anesthesia or impaired psychological condition.

\subsection{Management}

Following a detailed individual evaluation, parents were offered three possibilities: (1) close prenatal follow-up, without FCI with optimal timing of delivery; (2) fetal cardiac intervention; and (3) the termination of pregnancy. All the patients but three opted for an attempt of prenatal treatment. One mother decided to terminate the pregnancy due to a poor prognosis, and two others resigned after giving initial consent.

All of the FCI were percutaneous ultrasound-guided procedures. Three different ultrasound machines were used: Accuvix A30, probes: C2-61C, 2-6 MHz; Samsung WS80A, probes: CV1-8A, CA1-7A; and Epiq 7, probe C9-2. Ultrasound recordings were collected on DVDs or external drives.

Mothers' preoperative preparation was conducted according to the local protocol: eight hours preoperative fasting period was required, ranitidine and metoclopramide for prophylaxis of aspiration pneumonia $[19,20]$, intravenous hydration, and antibiotic prophylaxis $30 \mathrm{~min}$. before the intervention were administered.

\subsection{Anesthesia}

Eleven FCI were performed under general anesthesia, and 117 procedures were performed in conscious analgosedation of the mother with fentanyl and midazolam. After choosing the cardiac puncture site, we additionally performed maternal local anesthesia by 
injecting lidocaine along the planned needle trajectory from the skin to the uterine wall. The fetus was separately anesthetized with fentanyl $(20 \mathrm{mcg} / \mathrm{kg}$ EFW—estimated fetal weight), and atracurium ( $0.2 \mathrm{mg} / \mathrm{kg}$ EFW) administered into the umbilical vein [21-23].

\subsection{Cordocentesis and Cardiac Puncture}

All of the cordocenteses were performed with a 22-gauge needle (Spinocan, B. Braun Melsungen AG, Melsungen, Germany). For cardiac interventions, we used needles in two sizes: 18-gauge (Cook Medical Trocar Needle; Cook Medical Inc., Bloomington, IN, USA) and 17-gauge (Argon Medical Devices, Co-Axial Introducer needle, Argon Medical Devices Inc., Athens, TX, USA), depending on the balloon diameter. A 17-gauge needle was used for a balloon sized $4.5 \mathrm{~mm}$ or more. For pericardial drainage, a 20-gauge needle or a 21-gauge needle was used (Cook Medical Echotip Disposable Amniocentesis Needle; Cook Medical Inc., Bloomington, IN, USA). The technical details of the procedures were described in our previous papers $[15,24]$. In most cases, the whole procedure was performed with only two or three needle punctures (cordocentesis, cardiac puncture, and pericardial drainage or drug administration).

\subsection{Transplacental Fetal Treatment}

In order to improve fetal cardiac function, we introduced transplacental treatment with digoxin, using its positive inotropic effect. Before drug initiation, maternal contraindications for the therapy were excluded, a maternal electrocardiogram was performed, and serum potassium concentration was measured. A loading dose of $0.5 \mathrm{mg}$ given three times a day was administered to the pregnant woman for the first two days. Afterward, the maintenance dose of $0.25 \mathrm{mg}$ three times a day was continued. For maternal safety, we monitored the digoxin and potassium level in maternal serum, observed the clinical symptoms of digoxin overdosage, and performed electrocardiogram (ECG) monthly.

\subsection{Data Collection}

A database was created to collect the following parameters: maternal age, paternal age, maternal body mass index (BMI), family history of CHD, gestational age at intervention, gestational age at delivery, mode of delivery, number of uterus punctures, ASA (American Society of Anesthesiologists) physical status classification, method of anesthesia, and anesthesia-associated complications. Postoperative conditions, including nausea and vomiting requiring pharmacological intervention, postoperative pain demanding analgetic treatment, aspiration, the need for blood products transfusion within seven days after delivery, tocolysis administration, preterm birth, preterm prelabor rupture of membranes ( $\mathrm{pPROM}$ ), intrauterine infection (defined as the presence of the following findings: temperature $>38^{\circ} \mathrm{C}$, uterine tenderness, maternal tachycardia $>100 / \mathrm{min}$., fetal tachycardia $>160 /$ min [25]), the administration of digoxin, digoxin-related ailments, intensive care unit admission, and maternal death were also analyzed.

Patients were divided into four groups according to the type of fetal cardiac intervention: balloon aortic valvuloplasty (fBAV), balloon pulmonary valvuloplasty (fBPV), interatrial stent placement (IAS), and balloon atrioseptoplasty (BAS).

\subsection{Statistical Analysis}

Statistical analyses were performed with Statistica 13.3 (Tibco Software Inc., Palo Alto, CA, USA). The data were expressed as mean $\pm \mathrm{SD}$ or median with range, when appropriate. If there was a statistically significant difference between any two of the groups, $t$-student or non-parametric test was used, depending on the variable distribution. Differences between more than two groups were calculated with Kruskal-Wallis H test followed by a multiple comparison post-hoc test. Pearson and rho-Spearman correlations, and Fisher's exact test were also used, when appropriate. A $p$-value $<0.05$ was considered to be statistically significant. 


\section{Results}

\subsection{Number and Types of FCI}

Between June 2011 and April 2020, 128 fetal cardiac interventions were performed in 113 patients: 94 aortic balloon valvuloplasties in 88 patients; 15 pulmonary balloon valvuloplasties in 13 patients; 14 interatrial stent placements in 14 patients; and, five balloon atrial septoplasties in five patients. Figure 1 presents the number of fetal cardiac interventions performed yearly.

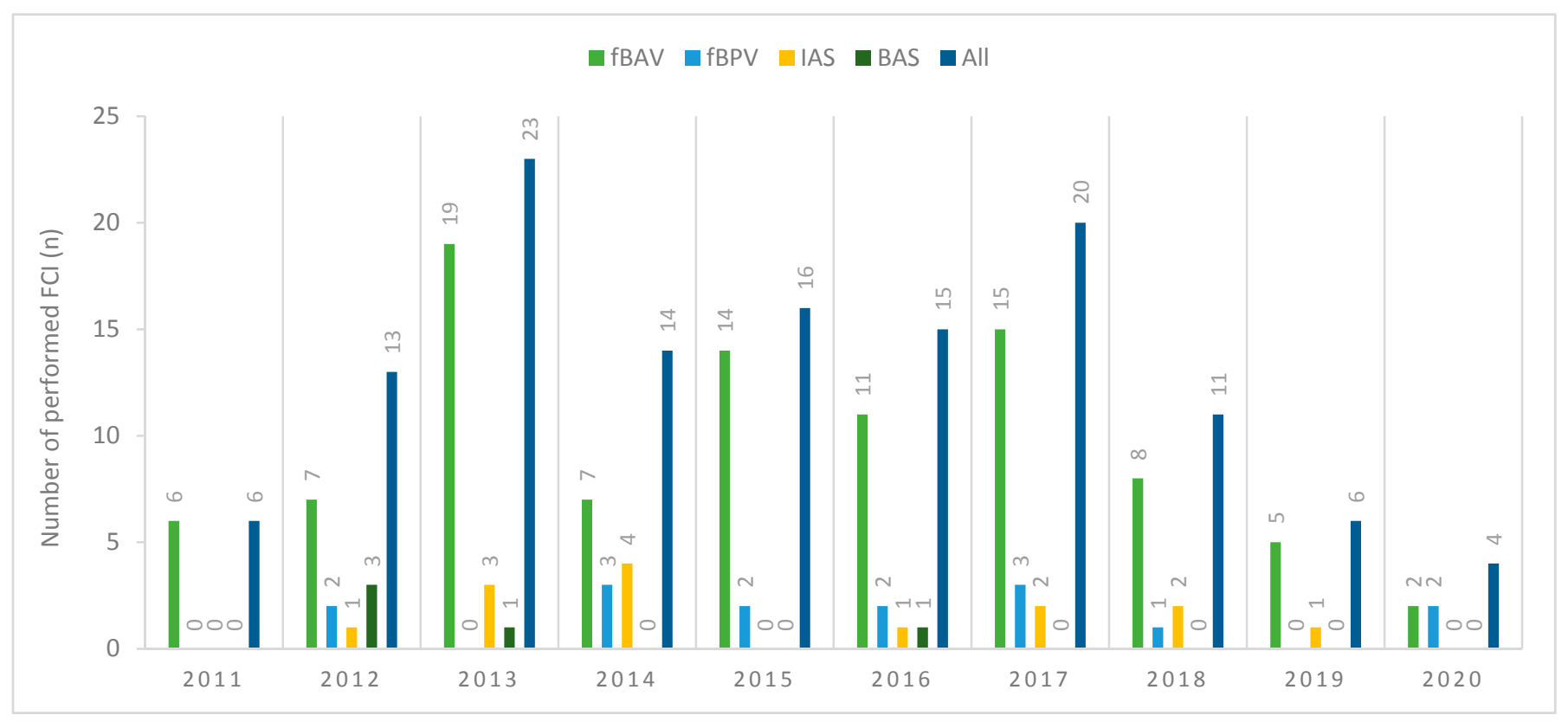

Figure 1. Number of fetal cardiac interventions (FCI) performed per year (from June 2011 until April 2020). fBAV: fetal balloon aortic valvuloplasty; fBPV: fetal balloon pulmonary valvuloplasty; IAS: interatrial stent placement; BAS: balloon atrial septoplasty; FCI: fetal cardiac intervention.

In eight mothers, the same procedure was performed twice due to either technical failure of the first FCI or disease progression, five patients had two different procedures, and one patient had three different procedures.

\subsection{Characteristics of the Patients}

112 patients (99\%) were Polish citizens, and all of them were Caucasian. One patient, referred to our center from Vietnam, was an American citizen. The median maternal age at FCI was 30 years (range 18-41), median paternal age was 32 years (range 20-54), with no significant differences between groups of procedures.

Before the procedure, the patients were consulted by an anesthesiologist. All of them were considered to be in good health, but as pregnant were automatically classified as ASA 2 [26].

The median BMI (body mass index) of the mothers was 24.6 (range 17.8-38.7); there was no difference in maternal BMI between the groups. Median gestational age at the first procedure was 25 weeks of gestation (range $20-32$ weeks). Four women (3.5\%) were active smokers during pregnancy and, in two of these pregnancies, intrauterine fetal demise classified as nonrelated to the procedure occurred.

Table 1 presents characteristics of the patients who underwent FCI according to the type of intervention. 
Table 1. Characteristics of the patients who underwent fetal FCI according to the type of intervention.

\begin{tabular}{|c|c|c|c|c|c|c|}
\hline Characteristic & $\begin{array}{c}\text { fBAV } \\
(n=88)\end{array}$ & $\begin{array}{c}\text { fBPV } \\
(n=13)\end{array}$ & $\begin{array}{c}\text { IAS } \\
(n=14)\end{array}$ & $\begin{array}{c}\text { BAS } \\
(n=5)\end{array}$ & $\begin{array}{c}\text { All } \\
(n=113)\end{array}$ & $p$-Value \\
\hline Maternal age at FCI (years) & $30(18-41)$ & $33(26-39)$ & $29(22-35)$ & $27(25-34)$ & $30(18-41)$ & 0.070 \\
\hline $\operatorname{BMI}\left(\mathrm{kg} / \mathrm{m}^{2}\right)$ & $\begin{array}{c}24.7 \\
(17.8-38.7)\end{array}$ & $\begin{array}{c}24.1 \\
(19.3-29.7)\end{array}$ & $\begin{array}{c}24.4 \\
(18.8-30.1)\end{array}$ & $\begin{array}{c}24.6 \\
(20.8-28.1)\end{array}$ & $\begin{array}{c}24.6 \\
(17.8-38.7)\end{array}$ & 0.650 \\
\hline $\begin{array}{c}\text { Obesity } \\
\left(\mathrm{BMI}>30 \mathrm{~kg} / \mathrm{m}^{2}\right)\end{array}$ & $14(15.9 \%)$ & $0(0 \%)$ & $1(7.1 \%)$ & $0(0 \%)$ & $15(13.3 \%)$ & 0.279 \\
\hline Gravidity & $2(1-5)$ & $2(1-5)$ & $2(1-3)$ & $2(2-5)$ & $2(1-5)$ & 0.433 \\
\hline Parity & $1(0-3)$ & $0(0-2)$ & $1(0-2)$ & $2(1-2)$ & $1(0-3)$ & 0.091 \\
\hline Active smoker & $4(4.5 \%)$ & $0(0 \%)$ & $0(0 \%)$ & $0(0 \%)$ & $4(3.5 \%)$ & 0.684 \\
\hline Paternal age (years) & $32(20-46)$ & $34(26-54)$ & $32(24-36)$ & $34(26-39)$ & $32(20-54)$ & 0.702 \\
\hline Family history of CHD & $8(9.1 \%)$ & $0(0 \%)$ & $0(0 \%)$ & $0(0 \%)$ & $8(7.1 \%)$ & 0.378 \\
\hline ASA physical status & ASA $2-100 \%$ & ASA $2-100 \%$ & ASA $2-100 \%$ & ASA $2-100 \%$ & ASA $2-100 \%$ & 1.000 \\
\hline
\end{tabular}

Data are given as median (range) or $n(\%) \cdot p$-value was calculated with the Kruskal-Wallis test. fBAV: fetal balloon aortic valvuloplasty; fBPV: fetal balloon pulmonary valvuloplasty; IAS: interatrial stent placement; BAS: balloon atrial septoplasty; FCI: fetal cardiac intervention; BMI: body mass index; CHD: congenital heart defect; ASA: American Society of Anesthesiologists.

\subsection{Technical Aspects of FCI}

All 128 procedures were performed under continuous ultrasound guidance with the percutaneous transabdominal approach. The placental location was posterior in $60 \%$ and anterior in $40 \%$ of cases. 115 procedures (90\%) were performed with an 18-gauge needle. During 13 procedures (10\%), a 17-gauge needle was used due to balloon diameter $4.5 \mathrm{~mm}$ or more. The median number of uterus needle punctures necessary to complete the procedure was 3 (range 2-11, no significant differences between the types of intervention) and 98 out of 128 procedures $(77 \%)$ were completed with no more than three punctures. More uterine punctures per procedure were observed in patients with posterior placenta (median 3, range $2-11$ vs. median 3 , range $2-5, p=0.016$ ). In those cases, we more easily decided to perform the intervention in cases with a suboptimal fetal position, which required additional needle maneuvers. Fetal cardiac tamponade decompression was necessary during 84 interventions (65\%). Eleven punctures were needed in one case of successful fetal resuscitation following a balloon rupture within the pulmonary artery.

\subsection{Threatened Premature Labor}

Tocolysis was not routinely administered-neither before, nor during, nor after the procedures. Only two patients developed transient preterm contractions following FCI. In both of them, short term tocolysis ( $48 \mathrm{~h}$ ) with betamimetics was successful. Finally, one of the patients delivered 69 days following the procedure (at 36 weeks and three days), and the second had an elective cesarean section in a different center, 41 days following the procedure (at 34 weeks of gestation). There were no preterm births due to the preterm uterine contractions that occurred within 10 days post-FCI. One patient (primigravida, 28 weeks of gestation) needed rescue cervical cerclage prior to the fetal cardiac intervention, due to preexistent cervical insufficiency (cervical length $11 \mathrm{~mm}$ ). The FCI was safely performed two days after successful cerclage.

\section{5. $p P R O M$}

None of the 128 procedures was complicated with procedure-related pPROM (defined as pPROM within 10 days following the intervention). There were nine cases of pre-existing polyhydramnios that are caused by fetal cardiac failure; six of them resolved following a successful FCI. In the remaining three cases, polyhydramnios persisted and in 2 of them resulted in later PPROM and preterm birth, which was nonrelated to the procedure.

\subsection{Postoperative Events}

No significant maternal bleeding occurred. There was one case of placental abruption that was related to the procedure, but the mother did not need any blood products transfusion. None of the mothers required intensive care unit admission. Postoperative nausea 
and vomiting on the day of intervention were reported by three patients-all of which had undergone general anesthesia with intubation. There were no other anesthesia-associated complications. All of the patients found anesthesia effective.

Eight patients reported mild abdominal pain post-FCI in the area of the punctures. It was usually observed in patients who required more needle punctures during the procedure (median 4.5, range 3-11 vs. median 3, range $2-6, p=0.001, r=0.32$ ). In all cases, the pain was sufficiently controlled with acetaminophen. None of the patients needed opioids administration following FCI.

Table 2 presents procedure information, maternal morbidity, and mortality.

Table 2. Perioperative data, maternal morbidity, and mortality for all 128 FCI procedures according to the type of intervention.

\begin{tabular}{|c|c|c|c|c|c|c|}
\hline & $\begin{array}{c}\text { fBAV } \\
(n=94)\end{array}$ & $\begin{array}{c}\text { fBPV } \\
(n=15)\end{array}$ & $\begin{array}{c}\text { IAS } \\
(n=14)\end{array}$ & $\begin{array}{c}\text { BAS } \\
(n=5)\end{array}$ & $\begin{array}{c}\text { Total } \\
(n=128)\end{array}$ & $p$-Value \\
\hline $\begin{array}{l}\text { Total number of uterus punctures } \\
\text { (cordocentesis, cardiac puncture, } \\
\text { decompression of tamponade, drug } \\
\text { administration) }\end{array}$ & $3(2-5)$ & $3(2-11)$ & $3(2-8)$ & $3(2-4)$ & $3(2-11)$ & 0.103 \\
\hline Tocolysis & $2(2.1 \%)$ & $0(0 \%)$ & $0(0 \%)$ & $0(0 \%)$ & $2(1.6 \%)$ & 0.866 \\
\hline Procedure-related pPROM \& & $0(0 \%)$ & $0(0 \%)$ & $0(0 \%)$ & $0(0 \%)$ & $0(0 \%)$ & 1.000 \\
\hline Procedure-related placental abruption $\$$ & $1(1.1 \%)$ & $0(0 \%)$ & $0(0 \%)$ & $0(0 \%)$ & $1(0.8 \%)$ & 0.948 \\
\hline Postoperative nausea and vomiting & $2(2.1 \%)$ & $0(0 \%)$ & $0(0 \%)$ & $1(20 \%)$ & $3(2.3 \%)$ & 0.058 \\
\hline Postoperative pain & $3(3.2 \%){ }^{\#}$ & $3(20 \%){ }^{\#}$ & $1(7.1 \%)$ & $1(20 \%)$ & $8(6.3 \%)$ & 0.048 \\
\hline Bleeding requiring blood transfusion & $0(0 \%)$ & $0(0 \%)$ & $0(0 \%)$ & $0(0 \%)$ & $0(0 \%)$ & 1.000 \\
\hline Chorioamnionitis & $0(0 \%)$ & $0(0 \%)$ & $0(0 \%)$ & $0(0 \%)$ & $0(0 \%)$ & 1.000 \\
\hline Wound infection & $0(0 \%)$ & $0(0 \%)$ & $0(0 \%)$ & $0(0 \%)$ & $0(0 \%)$ & 1.000 \\
\hline Post-FCI hospitalization (days) & $4(1-84)$ & $5(1-7)$ & $5(2-70)$ & $3(2-19)$ & $4(1-84)$ & 0.412 \\
\hline Intensive care unit admission & $0(0 \%)$ & $0(0 \%)$ & $0(0 \%)$ & $0(0 \%)$ & $0(0 \%)$ & 1.000 \\
\hline Intra-/perioperative maternal mortality & $0(0 \%)$ & $0(0 \%)$ & $0(0 \%)$ & $0(0 \%)$ & $0(0 \%)$ & 1.000 \\
\hline
\end{tabular}

Data are given as median (range) or $n(\%)$. $p$-value was calculated with Kruskal-Wallis test and multiple comparisons post-hoc test. fBAV: fetal balloon aortic valvuloplasty; fBPV: fetal balloon pulmonary valvuloplasty; IAS: interatrial stent placement; BAS: balloon atrial septoplasty; \& pPROM within 10 days from FCI; ${ }^{\$}$ placental abruption within 10 days from FCI; ${ }^{\#} p=0.009$.

\subsection{Digoxin Transplacental Therapy}

Ninety-two patients received digoxin postoperatively to improve fetal cardiac function. In 31 cases, the maintenance dose ( $0.25 \mathrm{mg}$ three times a day) was reduced due to side effects-mostly mild nausea and vomiting. Three mothers required hospital admission due to intensive nausea and vomiting while taking the drug. Only in one of them, digoxin serum concentration exceeded the therapeutic level 1.5-2.5 ng/mL [27], and it was $2.51 \mathrm{ng} / \mathrm{mL}$. In the other two cases, adverse effects occurred when the drug level was $1.55 \mathrm{ng} / \mathrm{mL}$ and $1.96 \mathrm{ng} / \mathrm{mL}$, respectively, and resolved soon after dose reduction.

All mothers who received digoxin had characteristic ECG changes (downsloping STsegment depression). None of them had severe ECG changes, which could be dangerous for them. There were no cases of digoxin therapy cessation due to abnormal ECG.

\subsection{Pregnancy Outcomes \\ 3.8.1. All Patients}

Median gestational age at delivery was 39 weeks (range 29-41). There were 100 live births (out of 113 pregnancies) - 89 term deliveries (89\%), and 11 preterm deliveries (11\%). Only six preterm deliveries occurred before 34 weeks of gestation.

The general rate of cesarean section was $46 \%$, and the value is similar to the general cesarean section rate in our country. The majority of operative deliveries was performed due to obstetric indications. In two cases, cesarean sections were performed to optimize the logistic conditions of the postnatal care. 
There were no terminations of pregnancy in the treated group. Intrauterine fetal demise related to the procedure occurred in nine cases. There was one procedure-related postnatal death following preterm delivery in the 25th week of gestation. In that case, placental abruption occurred within $48 \mathrm{~h}$ following the intervention. This complication possibly resulted from extensive needle maneuvers being performed through the anterior placenta to correct the fetal position. After that case, we avoided such maneuvers if the placenta was anterior. There were three cases of intrauterine fetal demise nonrelated to the procedure; in two of these cases, mothers were heavy smokers.

Table 3 presents data regarding pregnancy.

Table 3. Pregnancy outcomes according to the type of fetal cardiac intervention.

\begin{tabular}{|c|c|c|c|c|c|c|}
\hline & fBAV & fBPV & IAS & BAS & Total & $p$-Value \\
\hline $\begin{array}{c}\text { Number of procedures/number } \\
\text { of fetuses }\end{array}$ & $94 / 88$ & $15 / 13$ & $14 / 14$ & $5 / 5$ & $128 / 113$ & NA \\
\hline Gestational age at FCI (weeks) & $25(20-32)$ & $24(22-30)$ & $27(22-33)$ & $24(22-29)$ & $25(20-33)$ & 0.407 \\
\hline $\begin{array}{l}\text { Procedure-related death of the } \\
\text { fetus/neonate }{ }^{\dagger}\end{array}$ & 7 & 1 & 2 & 1 & 10 & 0.655 \\
\hline $\begin{array}{c}\text { Procedure non-related death of } \\
\text { the fetus }\end{array}$ & 3 & 0 & 0 & 0 & 3 & 0.776 \\
\hline Live birth & 78 & 12 & 12 & 4 & 100 & 0.889 \\
\hline Gestational age at birth (weeks) & $39(29-41)^{\S}$ & $38(33-40)$ & $37(29-41)$ & $33.5(29-39) \S$ & $39(29-41)$ & 0.041 \\
\hline Mode of delivery VD/CS & $\begin{array}{c}42 / 36 \\
54 \% / 46 \%\end{array}$ & $\begin{array}{c}6 / 6 \\
50 \% / 50 \%\end{array}$ & $\begin{array}{c}7 / 5 \\
58 \% / 42 \%\end{array}$ & $\begin{array}{c}3 / 1 \\
75 \% / 25 \%\end{array}$ & $\begin{array}{c}54 / 46 \\
54 \% / 46 \%\end{array}$ & 0.837 \\
\hline $\begin{array}{l}\text { Time interval between } \\
\text { intervention and birth (days) }\end{array}$ & $92(17-162)$ & $100(46-117)$ & $75(11-109)$ & $57.5(17-114)$ & $92(11-162)$ & 0.025 \\
\hline Birth weight (g) & $\begin{array}{c}3330 \\
(950-4950)^{\#}\end{array}$ & $\begin{array}{c}3130 \\
(2100-3920)\end{array}$ & $\begin{array}{c}3130 \\
(1770-4090)\end{array}$ & $\begin{array}{c}2640 \\
(1800-2860) \#,\end{array}$ & $\begin{array}{c}3320 \\
(950-4950)\end{array}$ & 0.046 \\
\hline
\end{tabular}

Data are given as median (range), number or \%. $p$-value calculated with the Kruskal-Wallis test and multiple comparisons post-hoc test. CS: cesarean section; VD: vaginal delivery; NA: not applicable; ${ }^{\dagger}$ procedure-related death-fetal/neonatal death within $72 \mathrm{~h}$ following the procedure; ${ }^{\S} p=0.030$ (fBAV vs. BAS); ${ }^{*} p=0.001$ (fBAV vs. BAS); $p=0.048$ (fBPV vs. BAS). Column "Total” is not the sum of previous columns, because in 14 patients more than one procedure was performed (the same FCI twice in eight cases, two different FCI in five cases, and three different FCI in one case).

\subsubsection{Patients Who Underwent More than One FCI}

Fourteen mothers underwent more than one procedure. In this group median gestational age at delivery was also 39 weeks (range 29-40). There were 13 live births $(93 \%)-10$ term deliveries $(77 \%)$ and three preterm deliveries $(23 \%)$. Only one preterm delivery occurred before 34 weeks of gestation. It was a pregnancy complicated with severe cardiac failure and polyhydramnios, where polyhydramnios persisted despite three different FCI and two amnioreductions. There was one case of procedure-related death in this group (7\%).

\section{Discussion}

Discussing the potential maternal risk of intrauterine intervention with the pregnant woman should be an inherent part of the consultation preceding every interventional fetal therapy. Intrauterine fetal procedures create exceptional conditions, in which at least, from the medical point of view, the mother does not benefit, but can suffer from potential complications. It is essential to minimalize maternal risk, which should never outweigh the possible improvement of the fetal condition. When running the FCI program at our center for the past nine years, we made an effort to improve not only the technical aspects of the procedures performed on the fetus, but also to ensure maternal safety.

\subsection{Anesthesia}

The first issue to discuss is the anesthesia for fetal therapy, which should ensure either safety or comfort for both the mother and the fetus [22,28]. The majority of FCI worldwide used to be performed under maternal general anesthesia with intubation, according to the published data $[3-5,29,30]$. However, this trend has been changing in recent years. 
It is well known that pregnant women are at an increased risk of difficult intubation and aspiration of digestive contents into the respiratory tract [31-33]. Therefore, healthy pregnant women are routinely considered by anesthesiologists as ASA 2 [26]. Failed intubation is the most common cause of anesthesia-related maternal death [34].

The initial eight FCI procedures were performed under general anesthesia with intubation, according to the literature available at that time. Each time we separately performed cordocentesis for either fetal blood sampling (to assess fetal karyotype and blood parameters) or separate anesthesia of the fetus (with fentanyl and atracurium).

Based on those procedures, we realized that, with the same route and number of needle punctures, we can provide efficient fetal anesthesia. Therefore, we moved from general anesthesia to the mother's conscious analgosedation. Moreover, before introducing the 18 or 17-gauge needle, we additionally injected lidocaine locally along the planned needle trajectory. Conscious maternal analgosedation, combined with local anesthesia of the puncture site, turned out to be sufficient for maternal anesthesia. The fetus was successfully anaesthetized separately with fentanyl and atracurium administered into the umbilical vein.

Henceforth, the mother's general anesthesia with intubation was only necessary in three cases due to FCI complications that prolonged the procedure and increased the number of uterine punctures.

Additionally, such anesthesia can be also offered to patients with high-risk intubation, e.g., patients with goiter, obesity, or other anatomical factors increasing the difficulty of intubation. Other benefits of conscious analgosedation of the mother include smaller doses of anesthetic drugs administered, the greater stability of her circulatory system, and more stable uteroplacental flow $[20,35,36]$. Following such anesthesia, patients were more likely to experience greater comfort, fewer adverse effects, and faster return to normal activity. In our group, we observed significantly less nausea and vomiting associated with anesthesia than reported by other authors [29].

\subsection{Approach}

All of the fetal cardiac interventions were performed through the needle inserted into the mother's abdomen under ultrasound guidance, which was consistent with most other reports [29,37-39], but it was not a uniformly applied route. The literature contains reports of performing laparotomy to optimize fetal position for needle procedure and enhance imaging resolution when the ultrasound probe was placed directly on the uterine wall $[4,30,40]$. This approach was used by some centers in the past, but it increased the risk of maternal complications, so it was abandoned.

In some cases, if the fetal position was not perfect, but close to optimal, it was possible to change it with the needle. In cases of an unfavorable fetal position, we first applied external maneuvers. Eventually, if fetal position was close to optimal, we corrected it with a 18/17-gauge needle that was inserted into the uterus for the cardiac procedure. If the position of the fetus was far from optimal, we waited for its spontaneous change asking mothers to take a walk or do same exercises. If this was unsuccessful, we postponed the intervention. Our experience shows that extensive maneuvers with the needle across the anterior placenta should be avoided in order to prevent placental bleeding or detachment.

\subsection{Uterine Punctures}

As mentioned before, the majority of procedures $(77 \%)$ only required two or three uterine punctures. In our opinion, such a minimally invasive approach resulted in the elimination of the need for tocolysis and prevented procedure-related pPROM, which was not observed in any of our patients.

In other types of prenatal therapy, the rate of maternal complications is higher [37]. According to the literature, the rate of PPROM after fetoscopy and open fetal surgery exceeds $30 \%$ [41-43]. Some of the authors provide data that the overall rate of maternal complica- 
tions after fetoscopy (such as chorioamnionitis, placental abruption, ICU-admission, and others) reaches $17.4 \%$ [41].

\subsection{Digoxin}

Our patients received postoperatively relatively high doses of digoxin, which could raise safety-related concern. The chosen dosing was based on the literature review $[27,44,45]$ and it has its background on given in the literature rate of the drug passing through the placenta to the fetus (feto-maternal ratio). Our results in this field will be addressed in another paper [46]. Nevertheless, complications that were related to digoxin toxicity were rare and mild.

Interestingly, the recommended drug serum level $(1.5 \mathrm{ng} / \mathrm{mL}-2.5 \mathrm{ng} / \mathrm{mL})$ was slightly exceeded in only one of the patients reporting side effects [27].

\subsection{The Course of Pregnancy and Delivery}

Our experience suggests that the influence of fetal cardiac interventions on pregnancy and delivery was negligible. In cases of successful fetal intervention, further course of pregnancy was uneventful and the performed intervention itself did not influence the time and mode of delivery. Moreover, as in most cases, polyhydramnios resulting from cardiac failure, resolved after the procedure, the FCI probably prevented pregnancy complications, like cervical shortening, preterm delivery, and mirror syndrome.

Neither FCI nor the fetal heart defect were indications for a cesarean section.

\subsection{Limitations of the Study}

The limitations of the study mainly concerned the groups that were covered by the study. Firstly, it was an observational single-center analysis, and the number of patients was relatively limited. Secondly the heterogeneity of the critical congenital heart diseases, the differences in patient selection criteria used between FCI centers and a variability of individual pregnancy course make comparing the outcomes difficult. However, despite all these limitations, intrauterine cardiac procedures could be offered, as very promising interventions to selected cases, taking the fact that these are relatively safe procedures to the mothers into account.

\section{Conclusions}

Maternal complications of any fetal intervention usually reflect the degree of its invasiveness (fetal approach, the type and size of devices used, and number of uterine punctures).

Fetal cardiac interventions are needle procedures are performed with relatively thin needle being introduced through the maternal abdominal layers under ultrasound guidance. If performed efficiently with minimum invasiveness by experienced operators in possibly safe and effective anesthesia, $\mathrm{FCI}$ are one of the safest for the mother's intrauterine procedures in modern prenatal therapy.

Conscious maternal analgosedation with separate fetal anesthesia can be successfully used in most FCI, avoiding complications of general anesthesia and not increasing the procedure-related pain.

In cases with pre-existing risk of preterm delivery (polyhydramnios, short cervix), the decision about the intervention should be made on an individual basis, weighting the risk of prematurity against the risk of fetal cardiovascular deterioration.

Digoxin dosage should be adjusted based on both clinical observations (maternal side effects, ECG changes) and the serum drug level, because there is no strong correlation between them. 
Author Contributions: Conceptualization, B.R., M.D., data curation B.R., A.K., A.G., K.C., A.S., J.W., J.S.-D., M.D.; formal analysis, B.R., A.G.; investigation, B.R., A.K., A.G., K.C., A.S., J.W., J.S.-D., M.D.; methodology, B.R., A.K., J.S.-D., M.D.; project administration, B.R., A.K., J.S.-D., MD; resources, B.R., A.K., A.G., K.C., J.S.-D., M.D.; supervision J.S.-D., M.D.; visualization, B.R., A.G., M.D.; writingoriginal draft preparation, B.R.; A.K., A.G., K.C., J.S.-D., M.D.; writing-review and editing, B.R., A.K., A.G., K.C., A.S., J.W., J.S.-D., M.D. All authors have read and agreed to the published version of the manuscript.

Funding: Between 2014 and 2020, this program was partially funded by the National Program of the Ministry of Health, titled "Program of complex intrauterine diagnosis and therapy as prophylaxis of consequences and complications of congenital fetal defects and diseases-as an element to improve fetal and neonatal condition". This program was conducted as a part of Centre of Postgraduate Medical Education scientific research.

Institutional Review Board Statement: The study was conducted according to the guidelines of the Declaration of Helsinki, and approved by the Ethics Committee of Centre of Postgraduate Medical Education.

Informed Consent Statement: Informed consent was obtained from all subjects analyzed prospectively. Patient consent was waived in the retrospective part of the study (with full anonymity of the included patients).

Data Availability Statement: The data presented in this study are available on request from the corresponding authors. The data are not publicly available due to privacy regulation.

Conflicts of Interest: The authors declare no conflict of interest.

\section{References}

1. Arzt, W.; Wertaschnigg, D.; Veit, I.; Klement, F.; Gitter, R.; Tulzer, G. Intrauterine aortic valvuloplasty in fetuses with critical aortic stenosis: Experience and results of 24 procedures. Ultrasound Obstet. Gynecol. 2011, 37, 689-695. [CrossRef]

2. McElhinney, D.B.; Marshall, A.C.; Wilkins-Haug, L.E.; Brown, D.W.; Benson, C.B.; Silva, V.; Marx, G.R.; Mizrahi-Arnaud, A.; Lock, J.E.; Tworetzky, W. Predictors of technical success and postnatal biventricular outcome after in utero aortic valvuloplasty for aortic stenosis with evolving hypoplastic left heart syndrome. Circulation 2009, 120, 1482-1490. [CrossRef] [PubMed]

3. Tworetzky, W.; McElhinney, D.B.; Marx, G.R.; Benson, C.B.; Brusseau, R.; Morash, D.; Wilkins-Haug, L.E.; Lock, J.E.; Marshall, A.C. In utero valvuloplasty for pulmonary atresia with hypoplastic right ventricle: Techniques and outcomes. Pediatrics 2009, 124, e510-e518. [CrossRef]

4. Wilkins-Haug, L.E.; Tworetzky, W.; Benson, C.B.; Marshall, A.C.; Jennings, R.W.; Lock, J.E. Factors affecting technical success of fetal aortic valve dilation. Ultrasound Obstet. Gynecol. 2006, 28, 47-52. [CrossRef] [PubMed]

5. Marshall, A.C.; van der Velde, M.E.; Tworetzky, W.; Gomez, C.A.; Wilkins-Haug, L.; Benson, C.B.; Jennings, R.W.; Lock, J.E. Creation of an Atrial Septal Defect In Utero for Fetuses With Hypoplastic Left Heart Syndrome and Intact or Highly Restrictive Atrial Septum. Circulation 2004, 110, 253-258. [CrossRef]

6. Arzt, W.; Tulzer, G. Fetal surgery for cardiac lesions. Prenat Diagn 2011, 31, 695-698. [CrossRef] [PubMed]

7. Galindo, A.; Gómez-Montes, E.; Gómez, O.; Bennasar, M.; Crispi, F.; Herraiz, I.; Mendoza, A.; Escribano, D.; García-Torres, E.; Carretero, J.M.; et al. Fetal Aortic Valvuloplasty: Experience and Results of Two Tertiary Centers in Spain. Fetal Diagn Ther. 2017, 42, 262-270. [CrossRef] [PubMed]

8. Crucean, A.; Alqahtani, A.; Barron, D.J.; Brawn, W.J.; Richardson, R.V.; O'Sullivan, J.; Anderson, R.H.; Henderson, D.J.; Chaudhry, B. Re-evaluation of hypoplastic left heart syndrome from a developmental and morphological perspective. Orphanet J. Rare Dis. 2017, 12, 138. [CrossRef] [PubMed]

9. Jantzen, D.W.; Moon-Grady, A.J.; Morris, S.A.; Armstrong, A.K.; Berg, C.; Dangel, J.; Fifer, C.G.; Frommelt, M.; Gembruch, U.; Herberg, U. Hypoplastic Left Heart Syndrome With Intact or Restrictive Atrial Septum: A Report From the International Fetal Cardiac Intervention Registry. Circulation 2017, 136, 1346-1349. [CrossRef] [PubMed]

10. Lowenthal, A.; Kipps, A.K.; Brook, M.M.; Meadows, J.; Azakie, A.; Moon-Grady, A.J. Prenatal diagnosis of atrial restriction in hypoplastic left heart syndrome is associated with decreased 2-year survival. Prenat Diagn. 2012, 32, 485-490. [CrossRef]

11. Vida, V.L.; Bacha, E.A.; Larrazabal, A.; Gauvreau, K.; Thiagaragan, R.; Fynn-Thompson, F.; Pigula, F.A.; Mayer, J.E.; Del Nido, P.J.; Tworetzky, W.; et al. Hypoplastic left heart syndrome with intact or highly restrictive atrial septum: Surgical experience from a single center. Ann Thorac. Surg. 2007, 84, 581-585. [CrossRef]

12. Glatz, J.A.; Tabbutt, S.; Gaynor, J.W.; Rome, J.J.; Montenegro, L.; Spray, T.L.; Rychik, J. Hypoplastic left heart syndrome with atrial level restriction in the era of prenatal diagnosis. Ann. Thorac. Surg. 2007, 84, 1633-1638. [CrossRef] [PubMed]

13. Hogan, W.J.; Grinenco, S.; Armstrong, A.; Devlieger, R.; Dangel, J.; Ferrer, Q.; Frommelt, M.; Galindo, A.; Gardiner, H.; Gelehrter, S.; et al. Fetal Cardiac Intervention for Pulmonary Atresia with Intact Ventricular Septum: International Fetal Cardiac Intervention Registry. FDT 2020, 47, 731-739. [CrossRef] [PubMed] 
14. Yuan, S.-M. Fetal cardiac interventions: An update of therapeutic options. Rev. Bras. Cir. Cardiovasc. 2014. [CrossRef]

15. Debska, M.; Kolesnik, A.; Rebizant, B.; Sekowska, A.; Grzyb, A.; Chaberek, K.; Witwicki, J.; Debski, R.; Dangel, J. Fetal Cardiac Interventions-Polish Experience from "Zero" to the Third World Largest Program. J. Clin. Med. 2020, 9, 2888. [CrossRef]

16. Kovacevic, A.; Öhman, A.; Tulzer, G.; Herberg, U.; Dangel, J.; Carvalho, J.S.; Fesslova, V.; Jicinska, H.; Sarkola, T.; Pedroza, C.; et al. Fetal hemodynamic response to aortic valvuloplasty and postnatal outcome: A European multicenter study. Ultrasound Obstet. Gynecol. 2018, 52, 221-229. [CrossRef] [PubMed]

17. McElhinney, D.B.; Tworetzky, W.; Lock, J.E. Current Status of Fetal Cardiac Intervention. Circulation 2010, 121, 1256-1263. [CrossRef]

18. Makikallio, K.; Levine, J.C.; Marx, G.R.; Colan, S.D.; Marshall, A.C.; Lock, J.E.; Tworetzky, W. Fetal aortic valve stenosis and the evolution of hypoplastic left heart syndrome: Patient selection for fetal intervention. Circulation 2006, 113, 1401-1405. [CrossRef]

19. Manchikanti, L.; Colliver, J.A.; Marrero, T.C.; Roush, J.R. Ranitidine and metoclopramide for prophylaxis of aspiration pneumonitis in elective surgery. Anesth Analg. 1984, 63, 903-910. [CrossRef]

20. Practice Guidelines for Obstetric Anesthesia: An Updated Report by the American Society of Anesthesiologists Task Force on Obstetric Anesthesia and the Society for Obstetric Anesthesia and Perinatology. Anesthesiology 2016, 124, 270-300. [CrossRef] [PubMed]

21. Hoagland, M.A.; Chatterjee, D. Anesthesia for fetal surgery. Paediatr. Anaesth. 2017, 27, 346-357. [CrossRef]

22. Van de Velde, M.; De Buck, F. Fetal and maternal analgesia/anesthesia for fetal procedures. Fetal Diagn 2012, 31, 201-209. [CrossRef] [PubMed]

23. Tran, K.M. Anesthesia for fetal surgery. Semin Fetal Neonatal Med. 2010, 15, 40-45. [CrossRef] [PubMed]

24. Dębska, M.; Szymkiewicz-Dangel, J.; Koleśnik, A.; Kretowicz, P.; Rebizant, B.; Witwicki, J.; Dębski, R. Fetal cardiac interventionsAre we ready for them? Ginekol. Pol. 2015, 86, 280-286. [CrossRef]

25. Tita, A.T.N.; Andrews, W.W. Diagnosis and management of clinical chorioamnionitis. Clin. Perinatol. 2010, 37, 339-354 [CrossRef] [PubMed]

26. Mayhew, D.; Mendonca, V.; Murthy, B.V.S. A review of ASA physical status-Historical perspectives and modern developments. Anaesthesia 2019, 74, 373-379. [CrossRef] [PubMed]

27. Hansmann, M.; Gembruch, U.; Bald, R.; Manz, M.; Redel, D.A. Fetal tachyarrhythmias: Transplacental and direct treatment of the fetus-A report of 60 cases. Ultrasound Obstet. Gynecol. 1991, 1, 162-170. [CrossRef]

28. Saxena, K.N. Anaesthesia for Fetal Surgeries. Indian J. Anaesth. 2009, 53, 554-559.

29. Wohlmuth, C.; Tulzer, G.; Arzt, W.; Gitter, R.; Wertaschnigg, D. Maternal aspects of fetal cardiac intervention. Ultrasound Obstet. Gynecol. 2014, 44, 532-537. [CrossRef]

30. Tworetzky, W.; Wilkins-Haug, L.; Jennings, R.W.; van der Velde, M.E.; Marshall, A.C.; Marx, G.R.; Colan, S.D.; Benson, C.B.; Lock, J.E.; Perry, S.B. Balloon dilation of severe aortic stenosis in the fetus: Potential for prevention of hypoplastic left heart syndrome: Candidate selection, technique, and results of successful intervention. Circulation 2004, 110, 2125-2131. [CrossRef]

31. Mushambi, M.C.; Kinsella, S.M.; Popat, M.; Swales, H.; Ramaswamy, K.K.; Winton, A.L.; Quinn, A.C. Obstetric Anaesthetists' Association and Difficult Airway Society guidelines for the management of difficult and failed tracheal intubation in obstetrics. Anaesthesia 2015, 70, 1286-1306. [CrossRef]

32. Biro, P. Difficult intubation in pregnancy. Curr. Opin. Anaesthesiol. 2011, 24, 249-254. [CrossRef] [PubMed]

33. Reitman, E.; Flood, P. Anaesthetic considerations for non-obstetric surgery during pregnancy. Br. J. Anaesth. 2011, 107 (Suppl. 1), i72-i78. [CrossRef]

34. Djabatey, E.A.; Barclay, P.M. Difficult and failed intubation in 3430 obstetric general anaesthetics. Anaesthesia 2009, 64, $1168-1171$. [CrossRef] [PubMed]

35. Nejdlova, M.; Johnson, T. Anaesthesia for non-obstetric procedures during pregnancy. Contin. Educ. Anaesth. Crit. Care Pain. 2012, 12, 203-206. [CrossRef]

36. Kuczkowski, K.M. The safety of anaesthetics in pregnant women. Expert Opin. Drug Saf. 2006, 5, 251-264. [CrossRef]

37. Gardiner, H.M. In utero intervention for severe congenital heart disease. Best Pract. Res. Clin. Obstet. Gynaecol. 2019, 58, 42-54. [CrossRef]

38. Gómez Montes, E.; Herraiz, I.; Mendoza, A.; Galindo, A. Fetal Intervention in Right Outflow Tract Obstructive Disease: Selection of Candidates and Results. Cardiol. Res. Pract. 2012, 2012, 1-8. [CrossRef] [PubMed]

39. Yuan, S.-M.; Humuruola, G. Fetal cardiac interventions: Clinical and experimental research. Postepy Kardiol. Interwencyjnej. 2016, 12, 99-107. [CrossRef] [PubMed]

40. Marshall, A.C.; Tworetzky, W.; Bergersen, L.; McElhinney, D.B.; Benson, C.B.; Jennings, R.W.; Wilkins-Haug, L.E.; Marx, G.R.; Lock, J.E. Aortic valvuloplasty in the fetus: Technical characteristics of successful balloon dilation. J. Pediatr. 2005, 147, 535-539. [CrossRef]

41. Merz, W.; Tchatcheva, K.; Gembruch, U.; Kohl, T. Maternal complications of fetoscopic laser photocoagulation (FLP) for treatment of twin-twin transfusion syndrome (TTTS). J. Perinat. Med. 2010, 38, 439-443. [CrossRef] [PubMed]

42. Moldenhauer, J.S.; Soni, S.; Rintoul, N.E.; Spinner, S.S.; Khalek, N.; Martinez-Poyer, J.; Flake, A.W.; Hedrick, H.L.; Peranteau, W.H.; Rendon, N.; et al. Fetal Myelomeningocele Repair: The Post-MOMS Experience at the Children's Hospital of Philadelphia. FDT 2015, 37, 235-240. [CrossRef] [PubMed]

43. Belfort, M.A. Predicting premature preterm rupture of the membranes after fetal surgery. BJOG Int. J. Obstet. Gynaecol. 2018, 125, 1293. [CrossRef] [PubMed] 
44. Strzelecka, I.; Respondek-Liberska, M.; Słodki, M.; Zych-Krekora, K.; Cuneo, B. Transplacental digoxin treatment in prenatal cardiac problems in singleton pregnancies-Meta analysis (based on literature: 1992-2015). Prenat. Cardiol. 2019, 2016, 67-74. [CrossRef]

45. Bravo-Valenzuela, N.J.; Rocha, L.A.; Machado Nardozza, L.M.; Júnior, E.A. Fetal cardiac arrhythmias: Current evidence. Ann. Pediatr. Cardiol. 2018, 11, 148-163. [PubMed]

46. Rebizant, B.; Chaberek, K.; Kolesnik, A.; Czapska, A.; Dangel, J.; Debska, M. VP14.15: Transplacental treatment: Digoxin levels in the mother and the fetus. Ultrasound Obstet. Gynecol. 2020, 56, 111-112. [CrossRef] 